\title{
Knowledge Management, Innovation and Organizational Performance
}

\author{
Samina Nawab, Tahira Nazir, Muhammad Mohsin Zahid, and Syed Muhammad Fawad
}

\begin{abstract}
In the 21st century the boundaries of business are expanding everyday and the management of different portfolios is not an easy task. Organizations are striving for innovation and to gain a competitive edge. Knowledge Management put emphasis on particularly this issue. This study has focused on the role of middle management in the implementation of knowledge management with the help of $\mathrm{KM}$ processes and strategies which eventually leads to innovation. Also the critical success factors of knowledge management on innovation are discussed in the study. The study concludes that the Knowledge Management processes which are Knowledge Creation, Knowledge organizing, Knowledge Storage , Knowledge Sharing \& Knowledge Utilization have significant but indirect impact on banking industry, and the results showed that these processes are contributing in the enhancement of innovation in banking industry
\end{abstract}

Index Terms-Knowledge management, organizational innovation, organizational performance.

\section{INTRODUCTION}

These days the use of information and knowledge has been increasing everyday in all types of organizations in order to simplify all the activities and enhance the process decisions making. The importance of managing the organizations information and knowledge becomes very vital. If a company does not have knowledge, it cannot manage itself to be a strong company. Knowledge management systems have become one of the fastest growing areas of corporate sector. We live in information economy in which the major source of wealth and prosperity is the production and distribution of information and knowledge.

Knowledge management (KM) has become an important theme at many large business firms as managers realize that much of their firm's value depends on the firm's ability to create and manage knowledge. Managers must play their role for effective knowledge management practices for gaining a sustainable competitive advantage which is the direction for innovation and better organizational performance. The competitive scenario of the domestic and global market heads up with the emergent need for smart management of knowledge in all aspects either within or outside the organization

Every day, organizations and their knowledge workers are facing problems in efficient knowledge management. The ability to create and distribute knowledge across the entire

Manuscript received December 10, 2014; revised February 15, 2015.

The authors are with the COMSATS Institute of Information Technology, Pakistan (e-mail: dr.saminanawab@comsats.edu.pk, tahiraasifpk@hotmail.com, shahfadi@yahoo.com). organization is therefore compelling drivers for knowledge management. It is imperative to study the effects of knowledge management practices on the organizational performance.

KM processes includes the creation of knowledge, organizing, storage, sharing and utilization of knowledge while the KM Strategies are codification and personalization. The modern society is moving towards knowledge society with a very fast pace; therefore knowledge is one of the ultimate source of competitive edge for most of the companies [1]. Every firm has its own competitive advantage in one way or the other. Knowledge can also be the competitive advantage for the firms. Knowledge management is acquiring, organizing, storing and disseminating the information within the organization. In a broad sense, when we define the term knowledge management than it means the course and process of frequently managing all kinds of knowledge in order to fulfill the needs, and to exploit existing and acquired knowledge for the new opportunities.

Advantages of Knowledge Management are not only facilitating the collaboration in the innovation process but also include identifying the gaps between knowledge base and remedies to fill the gaps. Above all knowledge management helps to flourish a knowledge-driven culture which fosters innovations [2]. Innovation is simply define as "the introduction of something new." Ref. [3] defined innovation in a simple way as "the generation, acceptance and implementation of new ideas, processes, products or services".

The middle managers are known as "Knowledge Engineers" in literature which actually starts the creation of new knowledge and is also responsible for the conversion of tacit knowledge from top managers (Knowledge Officers) and front line managers (Knowledge practitioners) into explicit knowledge. So middle managers play a key role in KM implementation. The knowledge engineers have to create knowledge and utilize knowledge for innovative work rather than just creating a bridge between top and front line managers [4]. There is a lack of empirical studies which examined the middle management role in knowledge management and innovation as well [5]. [6] elaborated leadership as the support of top management for the achievement of KM related activities. It is indicated that leadership is an important critical success factor (CSF) of $\mathrm{KM}$ and is also helpful in successful KM implementation. As the $\mathrm{KM}$ is a complex activity so it needs management leadership and support to achieve the highest level of organizational performance.

Ref. [7], [8] revealed that most researchers suggested that 
HRM is very much vital and crucial for the KM implementation in order to achieve organizational success. Ref. [9], [10], noted that HRM practices can improve the organizational knowledge. They also identified in their research that there are few studies regarding the use of HRM in managing knowledge. Ref. [11] showed that the knowledge accumulation capabilities are a source to enhance Organizational Innovation. In this regard [12] also found a direct effect of Knowledge Management processes on organizational innovation. Ref. [13] reported in their research that knowledge sharing and knowledge creation is very vital to improve innovation performance. Ref. [14] investigated the Critical Success Factors of knowledge creation which are organizational climate, organizational structure, strategy, system and procedures, leadership and personal characteristics. They further argued that these factors are major source of innovation processes in the organization. Ref [15] investigated the relationship between critical success factors of knowledge sharing and innovation. Ref. [16] contend that Knowledge Management processes are significant to improve overall Organizational Performance. In the same way [17] elaborated that knowledge utilization is considered as a critical and important part of the Knowledge Management processes. It has an ability to improve and achieve higher Organizational Performance. Ref. [18] noted that Knowledge Management processes which are knowledge acquisition, knowledge conversion, knowledge sharing and knowledge applications improves the Organizational Performance measured in terms of financial, market and partnership aspects. In the end the results indicate that Knowledge Management processes positively effects Organizational Performance.

Moreover, considering the Organizational Performance, [16] suggested that the Critical Success Factors of Knowledge Management are an appropriate tool for the improvement of Organizational Performance. They analyzed four Critical Success Factors of Knowledge Management which are Information Technology, Culture, Structure and people. The results of their study revealed positive effect of these critical success factors on Organizational Performance. They used the attributes which are growth rate, market share, general success and innovativeness. They also suggested the future researchers to conduct more research studies in this area. In the same way, [19] described self directed learning and organizational learning as Critical Success Factors of Knowledge Management and reported that the existence of an organization depends on increased Knowledge Management capabilities which can lead the organization towards the achievement of high Organizational Performance The results of the study revealed that self-directed learning and organizational learning have indirect positive effects on Organizational Performance. Ref. [20] proposed certain significant success factors of Knowledge Management which are culture, structure, and strategy. And these factors are useful for achieving high Organizational Performance

Ref. [20] considered the Critical Success Factors of Knowledge Management as the center and affection of Organizational Performance improvement. Ref. [21] stated that innovation has the potential and capability to improve organizational performance. Most of the organizations needed some support for innovation [15] also learning is an important driver of innovation which in turn improves organizational performance.

\section{CRitical Success Factors OF KM}

CSF's Of KM are those organizational factors that should be effectively addressed for the objective of successful implementation of knowledge management [22].

Ref. [23] identified and prioritized the twelve critical success factors of knowledge management. These factors are Management leadership and support, Organizational culture, KM strategy, Removal of resource constraints, Processes and activities, Human resource management, Organizational infrastructure, Performance measurement, Training and education, Information technology, Rewarding and motivation, Benchmarking. Considering this study management leadership and support, human resource management, training \& education and information technology were included because the banking sector of Pakistan has these prevailing common factors in their systems.

\section{A. Management Leadership and Support}

Leadership is considered as the support of top management for the achievement of KM related activities. Leadership is an important critical success factor of KM and is also helpful in successful KM implementation. As the KM is a complex activity so it needs management leadership and support to achieve the highest level of organizational performance. [23] identified and prioritized the twelve critical success factors of knowledge management. And the results of comparative study acknowledged that management leadership and support is the most important factor.

\section{B. Human Resource Management}

Ref. [7] revealed that most researchers suggested that HRM is very much vital and crucial for the KM implementation in order to achieve organizational success. Ref. [8] identified in his study that HRM practices influencing significantly in improving the organizational performance. The HRM practices he considered were HR planning, performance appraisals, staff training and development, compensation and security. Ref. [9] concluded in their research that HRM practices are one of the major factors for successful KM implementation. The HRM practices they considered were performance appraisal, compensation and staffing. Ref. [10] noted that HRM practices can improve the organizational knowledge. They also identified in their research that there are few studies regarding the use of HRM in managing knowledge.

\section{Training and Education}

Ref. [9] concluded in their research that HRM practices are one of the major factors for successful KM Implementation. The HRM practices they considered were training, performance appraisal, compensation and staffing.

\section{Information Technology}

Ref. [24] described that IT is an important factor in the organization and it can help employees to reduce time of 
knowledge transfer. And at the same time IT is also useful in achieving higher efficiency. IT is a useful organizational factor for maintaining new knowledge, knowledge transfer and knowledge storage. Ref. [22] noted that IT is useful factor in KM implementation and it can provide various tools such as databases, competitors information, clients information and easy access to specialized knowledge.

\section{KNOWledge MANAGEMENT Processes}

KM Processes includes knowledge creation, organizing, storage, sharing and utilization, and these processes are the systematic stages which provide the knowledge for the organization in order to succeed.

\section{A. Knowledge Creation}

Ref. [25] described organizational knowledge creation involves adding new components of knowledge and updating replacing the existing components. Ref. [26] described in their study that HRM is responsible for the employees who are the main source of knowledge creation. Ref. [27] recommended five ways of knowledge creation which are acquisition, dedicated resources, fusion, adaptation and knowledge networking.

\section{1) Acquisition}

The most effective way to get knowledge is to buy it. A company can buy from another company or hire individuals that have knowledge.

\section{2) Dedicated resources}

Some companies generate knowledge by establish units for specific purpose.

\section{3) Fusion}

Fusion is a method to create new synergy by bringing people from different departments to work together on a project.

\section{4) Adaptation}

Due to new products, new technologies, and social and economic changes drive company to change and adapt to survive in business.

\section{5) Knowledge networking}

Informal networking among people can create knowledge.

\section{B. Knowledge Organizing}

Ref. [28] indicated and referred the results of many empirical studies that many organizations can create knowledge but fail to properly organize and store that knowledge. They further define organizing knowledge are the mean by which knowledge from past experience and events influence present organization activities.

\section{Knowledge Storage}

Ref. [29] indicated that many empirical studied showed that organizations can create knowledge but fail to properly organize and store that knowledge. Ref. [30] intimated that organizational knowledge should be stored in a proper way. It includes knowledge in various forms like written documentation, codified human knowledge stored in an expert system, structured information stored in electronic databases, documented organizational procedures and processes and tacit knowledge acquired by individuals or network of individuals. While explicit knowledge should also be stored properly and it resides in unstructured documents in the form of memos, notes, meeting minutes etc. [31].

\section{Knowledge Sharing}

Ref. [32] elaborated that Sharing knowledge is not just sharing information. The purpose of knowledge sharing is to help a whole organization to reach its business goals. Ref. [27] $\backslash$ identified some barriers of knowledge sharing which are Lack of trust, Different cultures \& languages, Lack of time and meeting places, Narrow idea of productive work, Status and rewards go to knowledge owners, Lack of absorptive capacity in recipients, Belief that knowledge relates to specific groups and Intolerance for mistakes and lack of help.

\section{E. Knowledge Utilization}

Ref. [33] identified that knowledge utilization can be measured by a process containing several events depending on the individual or organization. It includes information transmission, information pickup, information processing and information application. These generic steps are essential to understand knowledge utilization. Ref. [34] made some important conceptual advances at that time and distinguished various purposes of utilization.

1) Raising an issue

2) Formulating new policies or programs

3) Evaluating alternatives

4) Improving existing programs

5) Mobilizing support

6) Changing ways of thinking

7) Planning new research

\section{KM PROCESSES AND INNOVATION}

This section of research explores the relationship between knowledge management processes and innovation with the help of past studies. The most commonly used Knowledge Management processes have been identified in the literature which are knowledge creation, knowledge organization, knowledge storage, knowledge sharing, and knowledge utilization.

The results of the research undertaken by [11] showed that the knowledge accumulation capabilities are a source to enhance Organizational Innovation. However the Knowledge Accumulation capabilities include storage, obtainment, selection, expansion and establishment of knowledge.

Ref. [35] studied knowledge acquisition, dissemination and responsiveness as Knowledge Management processes and the researchers found that knowledge dissemination does not have any effect on incremental innovation opposite to what they hypothesized. They further pointed out that there is a lack of empirical studies that examined the relationship between Knowledge Management and innovation. They further recommended more research studies in this regard should be conducted to confirm the contrary results obtained as what they hypothesized.

Ref. [36] investigated the relationship between knowledge accumulation capability and innovation. The knowledge 
accumulation capability includes storage, obtainment, selection, expansion and establishment of knowledge while innovation measured in terms of administrative and technical innovation. They further stated that knowledge accumulation capability is the major key in enhancing innovation. The results indicate that knowledge obtainment capability has a positive effect on administrative innovation as well as technical innovation while knowledge expansion capability also has a positive effect only on administrative innovation.

Ref. [37] studied the relationship between Knowledge Management Processes and innovation activities and the results of the research revealed the positive relationship between these factors. The Knowledge processes studied were acquisition of knowledge, dissemination of knowledge and utilization of knowledge. They further described that organization can be more innovative when it has the ability to create new knowledge.

Ref. [12] in this regard also investigated the relationship between Knowledge Management processes and innovation and found a direct effect of Knowledge Management processes on organizational innovation. The knowledge management processes include acquisition of knowledge, conversion of knowledge and application of knowledge while innovation measured in terms of product innovation and processes innovation. The researchers suggested more studies due to lack of empirical evidence that look into the relationship between knowledge management processes and innovation.

Ref. [38] investigated the relationship between tacit knowledge and innovation capability. The results of their research revealed that enhancing innovation capability depends on the degree of exploiting tacit knowledge in the organizations. They further elaborated that the organizations must know about the effect of internal factors on tacit knowledge.

Ref. [13] reported in their research that knowledge sharing and knowledge creation is very vital to improve innovation performance. The researchers hypothesized the relationship between knowledge sharing and knowledge creation and innovation performance and found the direct relationship among these factors.

Ref. [39] described in their research that persistent and consistency of Knowledge management processes is the best way to improve technological innovation. The results of the study showed the positive relationship between Knowledge Management Processes with product and service innovation. The knowledge management processes studied was acquisition, sharing and application of knowledge.

\section{SignificAnCE}

The competitive scenario of the local and global market heads up with the emergent need for smart management of knowledge in all aspects either within or outside the organization. Every day, organizations and their knowledge workers are facing problems in efficient knowledge management. The ability to create and distribute knowledge across the entire organization is therefore compelling drivers for knowledge management. It is imperative to study the effects of knowledge management practices on the organizational performance.

Understanding the knowledge management in terms of banking sector will highlight how it influences organizational performance. In response to this need, this research focuses on exploring the knowledge management processes and CSF's of knowledge management being used in the private commercial banks of Pakistan. The problem statement signifies the research questions which are to be answered through this research.

- What are the CSF's of knowledge management and their impact on the performance in private commercial banks of Pakistan?

- What are the knowledge management processes and their role in banking innovations?

- Do the banking innovations contribute to upscale the organizational performance?

- Are knowledge management processes being used to enhance the organizational performance through innovative products and services?

\section{DeVelopment And Refinement of Research Model}

The dependent variables are Innovation in the first phase and organizational Performance in the second phase. The present study while measuring innovation adopts the dimension of product and process innovation. On the other hand while measuring Organizational performance it adopts the dimensions of financial, process and internal performance. In the second phase the CSF's of KM, KM processes and Innovation were taken as Independent variables and Organizational performance as a dependant variable to test the significance.

\section{A. Phase 1}

In the first phase the CSF's of KM and KM processes were taken as Independent variables and innovation as a dependant variable to test the significance.

TABLE I: REGRESSION OF CSF AND KM PROCESSES

\begin{tabular}{ccccccc}
\hline \hline IV & DV & Beta & R & R Sq & t val & P Val \\
\hline CSF's of KM & Innov. & 0.02 & 0.63 & 0.40 & 0.23 & 0.81 \\
KM Process. & - & 0.61 & - & - & 7.44 & 0.00 \\
\hline \hline
\end{tabular}

\section{B. Phase 2}

In the second phase the CSF's of KM, KM processes and Innovation were taken as Independent variables and organizational performance as a dependant variable to test the significance.

TABLE II: REGRESSION FOR CSF OF KM, KM PROCESSES, INNOVATION \& ORGANIZATIONAL PERFORMANCE

\begin{tabular}{lcccccc}
\hline \multicolumn{1}{c}{ IV } & DV & Beta & R & R Sq & t & P \\
\hline CSF's of KM & OP & 0.30 & 0.75 & 0.56 & 4.35 & 0.00 \\
KM Process. & & 0.38 & & & 4.89 & 0.00 \\
Innovation & & 0.14 & & & 2.69 & 0.00 \\
\hline \hline
\end{tabular}

\section{Portraying the Full Path Model}

The model shown below in Fig. 1 is the merger of phase 1 and phase 2 . 


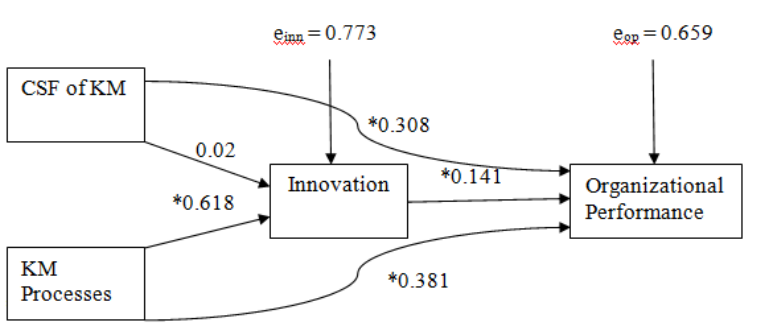

Fig. 1. Full path model.

\section{Portraying the Reduced Path Model}

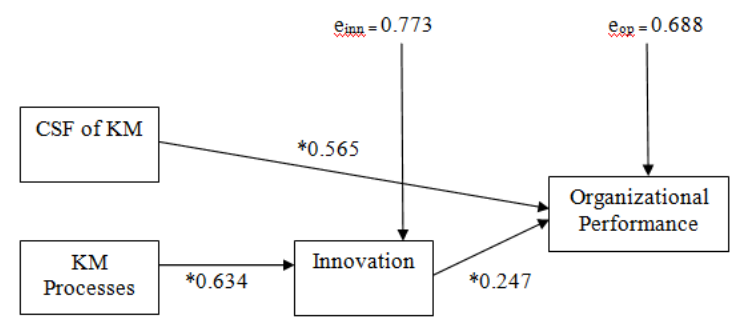

Fig. 2. Reduced path model.

TABLE III: REGRESSION FOR KM PROCESSES \& INNOVATION

\begin{tabular}{ccccccc}
\hline \hline IV & DV & Beta & R & R Sq & t & P \\
\hline KM Processes & Innov. & 0.63 & 0.63 & 0.40 & 13.41 & 0.00 \\
\hline \hline
\end{tabular}

TABLE IV: REGRESSION FOR CSF OF KM, INNOVATION \& ORGANIZATIONAL PERFORMANCE

\begin{tabular}{lllllll}
\hline \hline IV & DV & Beta & R & R Sq & t & P \\
\hline CSF's of KM & OP & 0.56 & 0.72 & 0.52 & 4.98 & 0.00 \\
Innovation & & 0.24 & & & 7.44 & 0.00 \\
\hline \hline
\end{tabular}

The test of the initial model indicates that the relationship between CSF of KM and innovation is less significant and further innovation and OP is not significant, that means CSF of KM has no direct impact on innovation in this scenario. We therefore exclude these relationships. For the reduced path model, represented as Fig. 2 results showed that the relationship between CSF of KM and OP is significant and the CSF of KM directly impacts OP. While the reduced model supports the intervening impact of innovation between KM Processes and OP significantly.

\section{E. Path Analysis}

"First Layer" multiple regression for the full model Innovation

$$
e=\sqrt{ }(1-r 2)=\sqrt{ }(1-0.402)=0.773
$$

"Second Layer" multiple regression for the full model OP

$$
e=\sqrt{ }(1-r 2)=\sqrt{ }(1-0.566)=0.659
$$

"First Layer" multiple regression for the Reduce Model Innovation

$$
e=\sqrt{ }(1-r 2)=\sqrt{ }(1-0.402)=0.773
$$

"Second Layer" multiple regression for the Reduce Model OP

$$
e=\sqrt{ }(1-r 2)=\sqrt{ }(1-0.527)=0.688
$$

\section{F. Testing the Reduced Model}

Fit of the full model

$$
1-(e 2)=1-0.773 \times 0.659=0.491
$$

Fit for the Reduced Model

$$
1-(e 2)=1-0.773 \times 0.688=0.482
$$

The significance test to compare the fit of the two models.

$$
W=-(N-d) \times \text { loge } 0.983=-(270-2) \times \text { loge } 0.983=4.595(7)
$$

$W$ is distributed as $\chi^{2}$ with $d f=d$. For this analysis

$$
\chi^{2}(\mathrm{df}=2, \mathrm{p}=0.05)=5.991
$$

The results of model fit are quite acceptable because the probability is highly significant.

\section{CONCLUSION}

This study concludes that the critical success factors of KM which are HRM, IT, Management leadership \& support and Training \& education have direct significant impact on banking industry, and the results showed that these factors are contributing towards the better and improved organizational performance in banking sector. The study also concludes that the KM processes which are Knowledge Creation, Knowledge organizing, Knowledge Storage, Knowledge Sharing \& Knowledge Utilization have significant but indirect impact on banking industry, and the results showed that these processes are contributing in the enhancement of innovation in banking industry. The presented study contributed to the previous studies through empirical evidence. The research contributes to academics and practitioners. The further studies should reexamine these variables to strengthen the results.

Banking sector can use this study to better understand the practices of knowledge management in banks and also the skills acquired or existing in the individuals working in the organization and is also helpful to cultivate a knowledge oriented environment. The level of organizational performance in the banking sector as a consequence of $\mathrm{KM}$ may capable of performing better compared with traditional tools to conduct the knowledge activities in the banks. Thus, the current system should be monitored, maintained, and evaluated continuously from time to time.

\section{REFERENCES}

[1] S. Salojärvi, P. Furu, and K.-E. Sveiby, "Knowledge management and growth in finnish SMEs," Journal of Knowledge Management, vol. 9 , pp. 103-122, 2005

[2] M. D. Plessis, "The role of knowledge management in innovation," Journal of Knowledge Management, vol. 11, pp. 20-29, 2007.

[3] V. A. Thompson, "Bureaucracy and innovation," Administrative Science Quarterly, pp. 1-20, 1965.

[4] S. Janczak, "How middle managers integrate knowledge within projects," Knowledge and Process Management, vol. 11, pp. 210-224, 2004.

[5] L. A. Y. Al-Hakim, "The relationships among critical success factors of knowledge management, innovation and organizational performance: A conceptual framework," 2011. 
[6] D. A. Asoh, S. Belardo, and J. Crnkovic, "Assessing knowledge management: Refining and cross validating the knowledge management index using structural equation modeling techniques," International Journal of Knowledge Management (IJKM), vol. 3, pp. 1-30, 2007.

[7] M. Gloet, "Knowledge management and the links to HRM: Developing leadership and management capabilities to support sustainability," Management Research News, vol. 29, pp. 402-413, 2006.

[8] Y. C. Lee and S. K. Lee, "Capabilities, processes, and performance of knowledge management: a structural approach," Human Factors and Ergonomics in Manufacturing \& Service Industries, vol. 17, pp. 21-41, 2007.

[9] C.-J. Chen and J.-W. Huang, "Strategic human resource practices and innovation performance-The mediating role of knowledge management capacity," Journal of Business Research, vol. 62, pp. 104-114, 2009

[10] A. Lopez-Cabrales, A. Pérez-Luño, and R. V. Cabrera, "Knowledge as a mediator between HRM practices and innovative activity," Human Resource Management, vol. 48, pp. 485-503, 2009.

[11] L. B. Cardinal, T. M. Alessandri, and S. F. Turner, "Knowledge codifiability, resources, and science-based innovation," Journal of Knowledge Management, vol. 5, pp. 195-204, 2001.

[12] T. L. Ju, C.-Y. Li, and T.-S. Lee, "A contingency model for knowledge management capability and innovation," Industrial Management \& Data Systems, vol. 106, pp. 855-877, 2006.

[13] X. Jiang and Y. Li, "An empirical investigation of knowledge management and innovative performance: The case of alliances," Research Policy, vol. 38, pp. 358-368, 2009.

[14] M. Merx-Chermin and W. J. Nijhof, "Factors influencing knowledge creation and innovation in an organisation," Journal of European Industrial Training, vol. 29, pp. 135-147, 2005.

[15] R.-J. Lin, R.-H. Chen, and K. K.-S. Chiu, "Customer relationship management and innovation capability: an empirical study," Industrial Management \& Data Systems, vol. 110, pp. 111-133, 2010.

[16] B. Choi and H. Lee, "An empirical investigation of KM styles and their effect on corporate performance," Information \& Management, vol. 40, pp. 403-417, 2003.

[17] M. R. Haas and M. T. Hansen, "When using knowledge can hurt performance: The value of organizational capabilities in a management consulting company," Strategic Management Journal, vol. 26, pp. 1-24, 2005.

[18] S.-H. Liao and C.-C. Wu, "The relationship among knowledge management, organizational learning, and organizational performance," International Journal of Business and Management, vol. 4, p. p64, 2009.

[19] L.-A. Ho, "What affects organizational performance?: The linking of learning and knowledge management," Industrial Management \& Data Systems, vol. 108, pp. 1234-1254, 2008.

[20] W. Zheng, B. Yang, and G. N. McLean, "Linking organizational culture, structure, strategy, and organizational effectiveness: Mediating role of knowledge management," Journal of Business Research, vol. 63 , pp. 763-771, 2010.

[21] K.-B. Ooi, P.-L. Teh, and A. Y.-L. Chong, "Developing an integrated model of TQM and HRM on KM activities," Management Research News, vol. 32, pp. 477-490, 2009.

[22] A. Carneiro, "How does knowledge management influence innovation and competitiveness?" Journal of Knowledge Management, vol. 4, pp. 87-98, 2000.

[23] V. Changiz, "Identification and prioritization of critical success factors of knowledge management in Iranian SMEs: An experts' view," African Journal of Business Management, vol. 4, pp. 915-924, 2010.

[24] A. Vaccaro, R. Parente, and F. M. Veloso, "Knowledge management tools, inter-organizational relationships, innovation and firm performance," Technological Forecasting and Social Change, vol. 77, pp. 1076-1089, 2010.

[25] B. T. Pentland, "Information systems and organizational learning: The social epistemology of organizational knowledge systems," Accounting, Management and Information Technologies, vol. 5, pp. 1-21, 1995.

[26] A. Monavvarian and Z. Khamda, "Towards successful knowledge management: People development approach," Business Strategy Series, vol. 11, pp. 20-42, 2010.

[27] T. H. Davenport and L. Prusak, Working Knowledge: How Organizations Manage What They Know, Harvard Business Press, 1998.
[28] E. W. Stein and V. Zwass, "Actualizing organizational memory with information systems," Information systems research, vol. 6, pp. 85-117, 1995.

[29] J. P. Walsh and G. R. Ungson, "Organizational memory," Academy of Management Review, vol. 16, pp. 57-91, 1991.

[30] S. Tan, H.-H. Teo, B. Tan, and K.-K. Wei, "Developing a preliminary framework for knowledge management in organizations," 1998.

[31] G. O. Dworman, S. O. Kimbrough, S. E. Kirk, and J. R. Oliver, "On relevance and two aspects of the organizational memory problem," Journal of Management Information Systems, 1997.

[32] D. Gurteen, "Creating a knowledge sharing culture," Knowledge Management Magazine, vol. 2, pp. 1-4, 1999.

[33] K. Larsen, "Review essay: Knowledge utilization what is it?" Science Communication, vol. 1, pp. 421-442, 1980.

[34] C. H. Weiss, "Knowledge creep and decision accretion," Science Communication, vol. 1, pp. 381-404, 1980.

[35] J. Darroch and R. McNaughton, "Examining the link between knowledge management practices and types of innovation," Journal of Intellectual Capital, vol. 3, pp. 210-222, 2002.

[36] S.-C. Chang and M.-S. Lee, "The linkage between knowledge accumulation capability and organizational innovation," Journal of Knowledge Management, vol. 12, pp. 3-20, 2008.

[37] A. Jantunen, "Knowledge-processing capabilities and innovative performance: an empirical study," European Journal of Innovation Management, vol. 8, pp. 336-349, 2005.

[38] X. Deyong, Z. Xiangyun, and Z. Qiuyue, "Empirical study on innovation competence based on tacit knowledge," in Proc. International Conference on Wireless Communications, Networking and Mobile Computing, 2007, pp. 5860-5863.

[39] C. L. Tan and A. M. Nasurdin, "Human resource management practices and organizational innovation: Assessing the mediating role of knowledge management effectiveness," Electronic Journal of Knowledge Management, vol. 9, pp. 155-167, 2011.

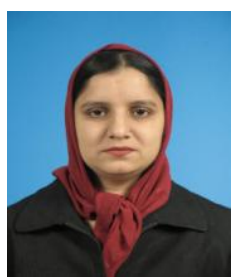

Samina Nawab earned her $\mathrm{PhD}$ in human resource management from the Institute of policy and Management, Graduate University of Chinese Academy of Sciences Beijing, China. Her research interests include human resource management, compensation management, human resource development, employee performance management and organizational behavior. She serves as the associate professor in COMSATS Institute of Information Technology, Pakistan.

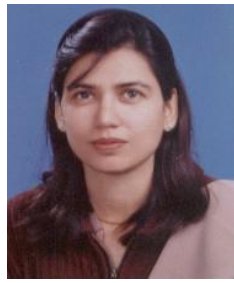

Tahira Nazir has her MSc in HRM from UK and is pursuing her $\mathrm{PhD}$ from Malaysia. She is interested in research about human resource management, human resource development, employee performance management and organizational behavior. She serves as the faculty member in the Department of Management Sciences, COMSATS Institute of Information Technology, Pakistan.

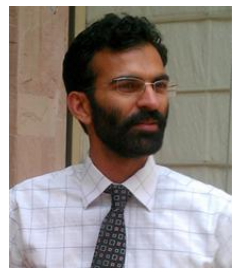

Muhammad Mohsin Zahid has the MS degree from Szabist, Pakistan. His areas of interest for research include contemporary consumer behavior especially in digital and social media, management education curriculum, and university-industry integration/collaboration.

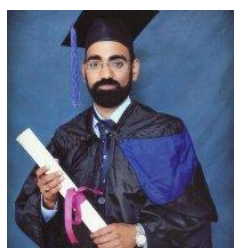

Syed Muhammad Fawad has the MS degree in human resource management. He has been associated with COMSATS Institute of Information Technology. His areas of interest include knowledge management and human resource management. 